\title{
Growth and Photosynthetic Responses of Litchi Seedlings to Arbuscular Mycorrhizal Fungal Inoculation: Differences between Two Genotypes
}

\author{
Yang $\mathrm{ZHOU}^{1}$, He CHANG ${ }^{1}$, Zengwei $\mathrm{FENG}^{1}$, Xiaodi LIU ${ }^{1}$, \\ Honghui $\mathrm{ZHU}^{2}$, Qing $\mathrm{YAO}^{1 *}$
${ }^{1}$ South China Agricultural University, College of Horticulture, Guangdong Engineering Research Center for Litchi, Guangzhou 510642, China; zhouyang9543@163.com;48550991@qq.com;napoleon2016@qq.com;786116180@qq.com; yaoqscau@scau.edu.cn (" ${ }^{*}$ corresponding author) Guangdong Provincial Microbial Culture Collection and Application Key Laboratory, Guangzhou 510070, China; zhubh@gdim.cn \\ ${ }^{2}$ Guangdong Institute of Microbiology, State Key Laboratory of Applied Microbiology (Ministry-Guangdong Province Jointly Breeding Base),
}

\begin{abstract}
Arbuscular mycorrhizal (AM) fungi are beneficial symbiotic soil microorganisms and AM technology can find its potential application in the nursery of horticultural industry. When AM fungi have been successfully applied to many wood fruit tree species, little information is available in litchi (Litchi chinensis Sonn.). In this study, the seedlings of two litchi genotypes ('Baila' and 'Heiye') were inoculated with two AM fungal species (Rhizophagus irregularis and Gigaspora margarita) in the nursery conditions, and the growth and photosynthetic responses of seedlings to AM fungal inoculation were investigated. Results indicated that AM fungi significantly promoted the plant growth of 'Heiye' seedlings in terms of biomass, plant height, stem diameter and leaf number, while they slightly decreased these parameters of 'Baila'. The inoculation effect can be explained by the changes in photosynthetic characteristics induced by AM fungi, because AM fungi increased $A_{\max }, A_{q e}$, LSP and decreased LCP of 'Heiye' but did not affected those of 'Baila'. $P_{n}$ was not affected by AM fungi, however, regression analysis indicated a weaker relationship between biomass and $P_{n}$ than those between biomass and $A_{\max }$, LSP or LCP. Our results strongly suggest that AM fungi can differentially affect the seedling growth of litchi genotypes mainly via their effects on photosynthetic characteristics, and that precautions should be taken to select appropriate genotypes as rootstock if AM technology is applied in litchi nursery.
\end{abstract}

Keywords: Gigaspora margarita; growth enhancement; Litchi chinensis; nursery; photosynthesis; Rhizophagus irregularis

\section{Introduction}

Litchi (Litchi chinensis Sonn.) is subtropical fruit tree native to the area between southern China, northern Viet Nam and Myanmar (Menzel, 2002). China is the leading litchi-producing country in the world with 950 thousand metric tons of production in 2002 (Jiang et al., 2012), however, most litchi orchards in China are located in hilly and marginal soils. These soils are typical of poor soil structure, low fertility and low pH (Wang et al., 2012), indicating the necessity of soil improvement and appropriate fertilization scheme in these orchards. In addition to those conventional strategies, however, some novel biotechnologies, such as arbuscular mycorrhizal (AM) technology, can also be relied on, especially when orchard sustainability is considered (Azcón-Aguilar and Barea, 1997). AM fungi (phylum Glomeromycota) are a kind of soil fungi, ubiquitous in all terrestrial ecosystems (Rillig, 2004). They establish symbiotic relationship with plant roots and, consequently, increase their host resistance to diverse biotic and/or abiotic stresses (Zhu and Yao, 2004; Zhu et al., 2007; Sensoy et al., 2013; Yao et al., 2014; Zou et al., 2014). Due to their multiple functions, Azcón-Aguilar and Barea (1997) regarded these symbiotic fungi as biofertilizers and bioprotectors in horticulture. In this context, it is clearly plausible to apply AM technology to the production of litchi in southern China.

The colonization of litchi plant roots by indigenous AM fungi in orchards has been frequently reported (Singh and Prasad, 2006; Sharma et al., 2009), and the diversity of these indigenous AM fungi has also been investigated (Mridha and Dhar, 2007; Sharma et al., 2009). It was found that root colonization of litchi plants and AM fungal spore density in the rhizosphere were as high as $65.42 \%$ and 2010 per $100 \mathrm{~g}$ dry soil in field conditions (Singh and Prasad, 2006). The Shannon's diversity index of indigenous AM fungi in litchi 
orchard soils was nearly 2.0, with Glomus species accounting for $83 \%$ (Mridha and Dhar, 2007). For the application of AM fungi to litchi production, the inoculation effect has been evaluated with either indigenous or exogenous AM fungal species. In an air-layer propagation system, Janos et al. (2001) found inoculation with the indigenous fungal species increased the aboveground biomass of litchi plants by $39 \%$ although the root colonization was only $7.4 \%$. Similarly, Sharma et al. (2009) inoculated the air-layers with four indigenous AM fungal species in combination with two Azotobacter chroococcum strains, and indicated that both AM fungi and Azotobacter promoted the total length of adventitious roots with a positive interactive effect. In an experiment using vermicompost as substrate, indigenous AM fungi promoted the plant height, leaf number and shoot length of air-layers by 132\%, 750\% and 68\% (Sagar and Roy, 2013). While these results demonstrate the potential application of AM fungi in the air-layer propagation system, grafting propagation system is widely recognized in China because seedlings in this system are more tolerant to stresses with better developing roots. Therefore, the evaluation of AM fungal inoculation effect on the growth of rootstock seedlings is of practical importance. Yao et al. (2005) reported that Glomus intraradices and Gigaspora margarita increased the biomass of rootstock seedlings by $13.5 \%-30.1 \%$ regardless of low root colonization $(<18.8 \%)$. The enhanced P uptake and phytohormones (IAA and iPAs) seemed to account for the changes in plant growth. In general, however, information of AM fungal effect on rootstock seedlings is very scarce.

Photosynthesis is the basis of carbohydrate accumulation in plants, and the improved photosynthesis together with enhanced nutrient uptake by AM fungi was demonstrated to contribute much to the increase in biomass of many plants (Birhane et al., 2012; Zhu et al., 2012). In our study, we focused on the effects of AM fungal inoculation on the photosynthetic characteristics, other than the nutrient status, of litchi rootstock seedlings, and meanwhile, the difference of two rootstock genotypes was also under investigation.

\section{Materials and Methods}

\section{Plant material, fungal species and substrate}

To investigate the AM fungal inoculation effect in nursery, all the steps in our study followed the procedure in litchi nursery in southern China, except that the sterilization and inoculation.

Two genotypes of litchi (Litchi chinensis Sonn.), 'Baila' and 'Heiye', were taken as rootstocks tested in our study. They were routinely used as rootstocks in litchi nursery due to the high quality seeds and vigorous seedlings. AM fungal species for inoculation were Rhizophagus irregularis (formerly known as Glomus intraradices) and Gigaspora margarita, which were used to colonized litchi seedlings in previous experiment (Yao et al., 2005). AM fungal inoculum was the mixture of soil, sands and colonized root fragments, propagated with clover and sorghum as host plants. Substrate for litchi propagation was the mixture of orchard soils, fermented chicken manure and peat (2:1:1 in volume), which followed the routine formula for litchi nursery. Orchard soils were from the litchi orchard of College of Horticulture, South China Agricultural University, while fermented chicken manure and peat were from the market. To exclude the indigenous AM fungal community, orchard soils and peat were sterilized using $\mathrm{Co}^{60}$ irradiation with dose of $20.0 \mathrm{kGy}$. The chemical properties of orchard soils were as follows: $\mathrm{pH} 5.25$, soil organic matter content $58.95 \mathrm{~g} \cdot \mathrm{kg}^{-1}$, total $\mathrm{N}$ content 2.29 $\mathrm{g} \cdot \mathrm{kg}^{-1}$, total P content $1.06 \mathrm{~g} \cdot \mathrm{kg}^{-1}$, total K content $8.63 \mathrm{~g} \cdot \mathrm{kg}^{-1}$, available $\mathrm{N}$ content $394.50 \mathrm{mg} \cdot \mathrm{kg}^{-1}$, available $\mathrm{P}$ content $40.13 \mathrm{mg} \cdot \mathrm{kg}^{-1}$, available K content $179.65 \mathrm{mg} \cdot \mathrm{kg}^{-1}$.

\section{Experimental design and seedling growth}

Litchi seeds were germinated in autoclaved vermiculite and let grow until the plant height reached $10-15 \mathrm{~cm}$. Then seedlings of similar vigor were transplanted to black plastic nursery bag of 7.85 liters ( 1 seedling per bag), with the substrate inoculated with $R$. irregularis, G. margarita or not inoculated (control). There were 3 inoculation treatments and 50 replicates for each treatment, thus producing 150 nursery bags in our study. Seedlings were placed in a glasshouse and grew for 12 months before harvest. The glasshouse was cooled at high temperature in summer but not heated at low temperature in winter, with temperature range of $18^{\circ} \mathrm{C}-30^{\circ} \mathrm{C}$ and natural light intensity. During the growth, seedlings were watered regularly and fertilized once at the sixth month with $200 \mathrm{mg} \mathrm{N}$ and $100 \mathrm{mg} \mathrm{K} \mathrm{per} \mathrm{kg}$ substrate.

\section{Measurement of parameters}

Before harvest, 10 seedlings were randomly taken out of 50 seedlings in each treatment for measurement of parameters. Plant height, leaf number and stem diameter were recorded. SPAD of the fully expanded leaves was measured using a chlorophyll meter (Minolta SPAD-502). After these non-destructive measurements, the photosynthesis of the seedlings was characterized using a portable photosynthesis system (Li-6400, Li-COR Biosciences Inc, Lincoln, USA). Then seedlings were carefully harvested, and roots were cut off and cleared of soils with tap water. Shoot fresh weight and root fresh weight were recorded. Accordingly, mycorrhizal dependency was calculated as $100 \% \times$ (biomass of inoculated seedling biomass of un-inoculated seedling) / biomass of inoculated (Yao et al., 2009). Chlorophyll was extracted and quantified according to Asmar $e t$ al. (2013). About $1 \mathrm{~g}$ fine roots were cut off for the quantification of AM fungal colonization. Briefly, root fragments of 1-2 cm length were stained according to Koske and Gemma (1989) and then observed under microscope at $\times 200$ magnifications. Root colonization, percentage of arbuscules and percentage of vesicles were quantified according to McGonigle et al. (1990).

Photosynthetic parameters were measured in the morning at 9:00-11:00. For the photosynthetic rate, stomatal conductance and transpiration rate, determination was performed at $25{ }^{\circ} \mathrm{C}$ with $60 \%$ relative humidity, 350 $\mu \mathrm{mol} \cdot \mathrm{mol}^{-1} \mathrm{CO}_{2}$ concentration and $1000 \mu \mathrm{mol} \cdot \mathrm{m}^{-2} \cdot \mathrm{s}^{-1}$ light intensity. For plotting the light response curve, light intensity was set at 20,50,100,300, 500, 800, 1000, 1200, 1400, 1600, 1800, $2000 \mu \mathrm{mol} \cdot \mathrm{m}^{-2} \cdot \mathrm{s}^{-1}$ with other conditions the same as above. 
468

\section{Statistical analyses}

All data were the average of ten replicates. Two-way analysis of variance (ANOVA) and multiple range test (Tukey's) were performed using SPSS 17.0 software (SPSS Inc., Chicago, USA). Light response curves were fitted by nonlinear regression with the Mitscherlich model equation using SigmaPlot 12.5 software (SSPS Inc., Chicago, USA) as follows: $A=A_{\max }\left[1-e^{-A g e(P P F D-L C P)}\right]$, where $A$ is net photosynthesis $\left(\mathrm{P}_{\mathrm{n}}\right), \mathrm{A}_{\max }$ refers to the asymptote of photosynthesis, $\mathrm{A}_{\mathrm{qc}}$ represents the apparent quantum yield or initial slope of the curve, PPFD is the incident photosynthetic photon flux density, and the LCP refers to the light compensation point that corresponds to the $\mathrm{x}$ intercept (where photosynthetic uptake and respiratory $\mathrm{CO}_{2}$ release are in equilibrium). The calculation of $\mathrm{A}_{\max }, \mathrm{A}_{\mathrm{qc}}$, LCP, light saturation point (LSP) and dark respiration rate $\left(\mathrm{R}_{\mathrm{d}}\right)$ was according to Aleric and Kirkman (2005). Relationships between shoot biomass and $\mathrm{P}_{n}, \mathrm{~A}_{\max }, \mathrm{LCP}$ or LSP were analyzed with linear regression using SigmaPlot 12.5 software.

\section{Results}

\section{AM fungal colonization in the roots of rootstock seedlings}

Data in Table 1 showed that both $R$. irregularis and $G$. margarita colonized the roots well, with colonization rate varying between $54.4 \%$ and $74.8 \%$. When the percentages of arbuscules in roots were $10.3 \%-18.3 \%$, the percentages of vesicles in roots colonized by $R$. irregularis were only 2.2\%$5.8 \%$ with no vesicles present in those colonized by $G$. margarita. It is clear that all these three parameters of 'Heiye' were significantly higher than those of 'Baila' (Table 1). There is no significant interaction between genotype and inoculation. seedlings

AM fungal inoculation effect on the growth of rootstock

It is clear that shoot biomass and plant height of 'Baila' were significantly higher than those of 'Heiye' and inoculation significantly affected shoot biomass, stem diameter and leaf number (Table 2). Data indicated that AM fungi promoted the seedling growth of 'Heiye' but not of 'Baila' (Table 2). In detail, both $R$. irregularis and $G$. margarita significantly increased the shoot biomass of 'Heiye' although the root biomass was not affected. In contrast, $R$. irregularis significantly decreased both shoot biomass and root biomass of 'Baila', and G. margarita showed no effect. For plant height and stem diameter, AM fungal inoculation effect exhibited similar patterns to that for the biomass except that $G$. margarita showed no inoculation effect on 'Heiye' (Table 2). For leaf number, both $R$. irregularis and $G$. margarita did not affect 'Baila' but significantly increased that of 'Heiye' (Table 2).

In general, AM fungal inoculation promoted the seedling growth of 'Heiye', but did not affect and even decreased the seedling growth of 'Baila'. Accordingly, the mycorrhizal dependencies of 'Heiye' were $17.4 \%(R$. irregularis) and $12.1 \%$ (G. margarita), while those of 'Baila' were $-31.7 \%$ (R. irregularis) and 3.5\% (G. margarita) (Table $2)$. These data demonstrate the great difference in the growth responses of 'Baila' and 'Heiye' seedlings to AM fungal inoculation.

AM fungal inoculation effect on the photosynthetic characteristics of rootstock seedlings

Data in Table 3 indicate that chlorophyll contents in the leaves of 'Heiye' were much higher than those of 'Baila', and in contrast, the transpiration rate of 'Heiye' was lower than that of 'Baila'. AM fungal inoculation significantly increased SPAD values but decreased the stoma conductivity and transpiration rate.

For 'Baila', both R. irregularis and G. margarita did not significantly affect SPAD value, chlorophyll contents, net photosynthesis, stoma conductivity and transpiration rate (Table 3). For 'Heiye', chlorophyll contents were not affected by AM fungal, while SPAD value was significantly increased. When $R$. inregularis slightly increased the net photosynthesis, stoma conductivity and transpiration rate, G. margarita slightly decreased them (Table 3). No significant difference between non-inoculated and inoculated seedlings was observed, while significant difference between seedlings inoculated with two AM fungal species was observed (Table 3). Light response curves of seedlings were fitted by nonlinear regression (Fig. 1).

Table 1. Root colonization, percentage of arbuscules and percentage of vesicles by AM fungi in the seedling roots of 'Baila' and 'Heiye'

\begin{tabular}{|c|c|c|c|}
\hline Inoculation treatments & Root colonization (\%) & Percentage of arbuscules (\%) & Percentage of vesicles (\%) \\
\hline \multicolumn{4}{|c|}{ 'Baila' } \\
\hline Non-inoculation & $0 \pm 0 \mathrm{~b}$ & $0 \pm 0 \mathrm{~b}$ & $0 \pm 0 \mathrm{~b}$ \\
\hline Rhizophagus irregularis & $54.4 \pm 4.8 \mathrm{a}$ & $10.3 \pm 1.3 \mathrm{a}$ & $2.2 \pm 0.6 \mathrm{a}$ \\
\hline Gigaspora margarita & $57.8 \pm 4.6 \mathrm{a}$ & $13.3 \pm 2.0 \mathrm{a}$ & NA \\
\hline \multicolumn{4}{|c|}{ 'Heiye’ } \\
\hline Non-inoculation & $0 \pm 0 \mathrm{c}$ & $0 \pm 0 \mathrm{~b}$ & $0 \pm 0 \mathrm{~b}$ \\
\hline Rhizophagus irregularis & $74.6 \pm 4.5 \mathrm{a}$ & $16.9 \pm 1.8 \mathrm{a}$ & $5.8 \pm 1.6 \mathrm{a}$ \\
\hline Gigaspora margarita & $57.8 \pm 4.7 \mathrm{~b}$ & $18.3 \pm 1.9 \mathrm{a}$ & NA \\
\hline \multicolumn{4}{|c|}{ Two-way ANOVA } \\
\hline Cultivar & * & * & * \\
\hline Inoculation & *** & *** & ** \\
\hline Cultivar× Inoculation & ns & ns & ns \\
\hline
\end{tabular}


Table 2. Influence of AM fungal inoculation on the biomass, plant height, stem diameter and leaf number of 'Baila' and 'Heiye' seedlings and their mycorrhizal dependencies

\begin{tabular}{|c|c|c|c|c|c|c|}
\hline Inoculation treatments & Shoot FW (g) & Root FW (g) & Plant height $(\mathrm{cm})$ & Stem diameter $(\mathrm{mm})$ & Leaf number & Mycorrhizal dependency (\%) \\
\hline \multicolumn{7}{|c|}{ 'Baila' } \\
\hline Non-inoculation & $34.3 \pm 2.0 \mathrm{a}$ & $7.3 \pm 0.9 \mathrm{a}$ & $51.4 \pm 1.8 \mathrm{a}$ & $6.1 \pm 0.1 \mathrm{ab}$ & $22.1 \pm 1.4 \mathrm{a}$ & - \\
\hline Rhizophagus irregularis & $26.4 \pm 2.2 \mathrm{~b}$ & $5.3 \pm 0.4 b$ & $47.3 \pm 1.1 \mathrm{~b}$ & $5.8 \pm 0.1 b$ & $20.4 \pm 1.1 \mathrm{a}$ & -31.2 \\
\hline Gigaspora margarita & $36.2 \pm 3.2 \mathrm{a}$ & $6.9 \pm 0.9 \mathrm{a}$ & $50.5 \pm 1.0 \mathrm{ab}$ & $6.5 \pm 0.1 \mathrm{a}$ & $21.5 \pm 1.8 \mathrm{a}$ & 3.5 \\
\hline \multicolumn{7}{|c|}{ 'Heiye' } \\
\hline Non-inoculation & $21.7 \pm 2.5 b$ & $5.9 \pm 0.5 \mathrm{a}$ & $43.1 \pm 1.8 \mathrm{~b}$ & $5.8 \pm 0.2 b$ & $21.1 \pm 1.6 \mathrm{~b}$ & - \\
\hline Rhizophagus irregularis & $27.7 \pm 2.0 \mathrm{a}$ & $5.7 \pm 0.6 \mathrm{a}$ & $48.5 \pm 1.7 \mathrm{a}$ & $6.3 \pm 0.2 \mathrm{a}$ & $25.9 \pm 1.8 \mathrm{a}$ & 17.4 \\
\hline Gigaspora margarita & $26.1 \pm 0.6 \mathrm{a}$ & $5.3 \pm 0.6 \mathrm{a}$ & $44.8 \pm 1.1 \mathrm{ab}$ & $5.8 \pm 0.1 \mathrm{~b}$ & $24.5 \pm 1.5 \mathrm{a}$ & 12.1 \\
\hline \multicolumn{7}{|c|}{ Two-way ANOVA } \\
\hline Cultivar & * & ns & * & ns & ns & \\
\hline Inoculation & * & ns & ns & * & * & \\
\hline Cultivar× Inoculation & ns & ns & * & ns & * & \\
\hline
\end{tabular}

Table 3. Influence of AM fungal inoculation on the photosynthetic characteristic of 'Baila' and 'Heiye' seedlings

\begin{tabular}{|c|c|c|c|c|c|c|}
\hline Inoculation treatments & SPAD value & $\begin{array}{l}\text { Chla content } \\
\left(\mathrm{mg} \cdot \mathrm{g}^{-1}\right)\end{array}$ & $\begin{array}{l}\text { Chlb content } \\
\left(\mathrm{mg}^{-g^{-1}}\right)\end{array}$ & $\begin{array}{c}\mathrm{Pn}(\mu \mathrm{mol} \\
\left.\mathrm{CO}_{2} \cdot \mathrm{m}^{-2} \cdot \mathrm{s}^{-1}\right)\end{array}$ & $\begin{array}{c}\mathrm{Cs}(\mathrm{mmol} \\
\left.\mathrm{H}_{2} \mathrm{O} \cdot \mathrm{m}^{-2} \cdot \mathrm{s}^{-1}\right)\end{array}$ & $\begin{array}{c}\mathrm{Tr}\left(\mathrm{mmol} \mathrm{H}_{2} \mathrm{O}\right. \\
\left.\mathrm{m}^{-2} \cdot \mathrm{s}^{-1}\right)\end{array}$ \\
\hline \multicolumn{7}{|c|}{ 'Baila' } \\
\hline Non-inoculation & $47.1 \pm 0.7 \mathrm{a}$ & $0.09 \pm 0.02 \mathrm{a}$ & $0.20 \pm 0.05 \mathrm{a}$ & $4.18 \pm 0.63 \mathrm{a}$ & $8.0 \pm 1.3 \mathrm{a}$ & $0.43 \pm 0.07 \mathrm{a}$ \\
\hline Rhizophagus irregularis & $47.4 \pm 1.1 \mathrm{a}$ & $0.08 \pm 0.01 \mathrm{a}$ & $0.15 \pm 0.02 \mathrm{a}$ & $4.06 \pm 0.47 \mathrm{a}$ & $7.2 \pm 1.2 \mathrm{a}$ & $0.40 \pm 0.06 \mathrm{a}$ \\
\hline Gigaspora margarita & $48.0 \pm 0.8 \mathrm{a}$ & $0.10 \pm 0.01 \mathrm{a}$ & $0.19 \pm 0.02 \mathrm{a}$ & $3.82 \pm 0.35 \mathrm{a}$ & $6.7 \pm 1.0 \mathrm{a}$ & $0.37 \pm 0.05 \mathrm{a}$ \\
\hline \multicolumn{7}{|c|}{ 'Heiye' } \\
\hline Non-inoculation & $43.2 \pm 1.0 \mathrm{~b}$ & $0.14 \pm 0.01 \mathrm{a}$ & $0.35 \pm 0.02 \mathrm{a}$ & $3.87 \pm 0.31 \mathrm{ab}$ & $7.1 \pm 1.0 \mathrm{ab}$ & $0.38 \pm 0.03 \mathrm{ab}$ \\
\hline Rhizophagus irregularis & $47.3 \pm 09 \mathrm{a}$ & $0.16 \pm 0.01 \mathrm{a}$ & $0.40 \pm 0.02 \mathrm{a}$ & $4.58 \pm 0.48 \mathrm{a}$ & $8.2 \pm 0.7 \mathrm{a}$ & $0.44 \pm 0.06 \mathrm{a}$ \\
\hline Gigaspora margarita & $46.8 \pm 1.0 \mathrm{a}$ & $0.16 \pm 0.01 \mathrm{a}$ & $0.39 \pm 0.02 \mathrm{a}$ & $2.88 \pm 0.31 \mathrm{~b}$ & $5.4 \pm 0.8 \mathrm{~b}$ & $0.29 \pm 0.03 \mathrm{~b}$ \\
\hline \multicolumn{7}{|c|}{ Two-way ANOVA } \\
\hline Cultivar & ns & * & * & $\mathrm{ns}$ & ns & * \\
\hline Inoculation & * & ns & ns & ns & * & * \\
\hline Cultivar $\times$ Inoculation & ns & ns & ns & $\mathrm{ns}$ & ns & ns \\
\hline
\end{tabular}

Table 4. Influence of AM fungal inoculation on the light response curves of 'Baila' and 'Heiye' seedlings

\begin{tabular}{|c|c|c|c|c|c|}
\hline Inoculation treatments & $\mathrm{A}_{\max }\left(\mu \mathrm{mol} \mathrm{CO} 2 \cdot \mathrm{m}^{-2} \cdot \mathrm{s}^{-1}\right)$ & $\mathrm{A}_{\mathrm{qe}}$ & $\mathrm{LCP}\left(\mu \mathrm{mol} \cdot \mathrm{m}^{-2} \cdot \mathrm{s}^{-1}\right)$ & $\operatorname{LSP}\left(\mu \mathrm{mol} \cdot \mathrm{m}^{-2} \cdot \mathrm{s}^{-1}\right)$ & $\mathrm{R}_{\mathrm{d}}\left(\mu \mathrm{mol} \mathrm{CO} \mathrm{CO}_{2} \cdot \mathrm{m}^{-2} \cdot \mathrm{s}^{-1}\right)$ \\
\hline \multicolumn{6}{|c|}{ 'Baila' } \\
\hline Non-inoculation & $6.65 \pm 0.42 \mathrm{a}$ & $0.05 \pm 0.01 \mathrm{a}$ & $7.95 \pm 0.84 \mathrm{ab}$ & $611.26 \pm 48.63 \mathrm{a}$ & $-0.40 \pm 0.04 \mathrm{a}$ \\
\hline Rhizophagus irregularis & $7.67 \pm 0.30 \mathrm{a}$ & $0.10 \pm 0.05 \mathrm{a}$ & $6.75 \pm 0.85 b$ & $678.26 \pm 52.10 \mathrm{a}$ & $-0.33 \pm 0.04 \mathrm{a}$ \\
\hline Gigaspora margarita & $7.00 \pm 0.34 \mathrm{a}$ & $0.10 \pm 0.05 \mathrm{a}$ & $9.68 \pm 1.11 \mathrm{a}$ & $731.76 \pm 57.84 \mathrm{a}$ & $-0.46 \pm 0.07 a$ \\
\hline \multicolumn{6}{|c|}{ 'Heiye' } \\
\hline Non-inoculation & $3.99 \pm 0.14 b$ & $0.02 \pm 0.00 \mathrm{~b}$ & $41.96 \pm 17.98 \mathrm{a}$ & $429.67 \pm 41.86 b$ & $-0.75 \pm 0.05 a$ \\
\hline Rhizophagus irregularis & $6.40 \pm 0.22 \mathrm{a}$ & $0.04 \pm 0.02 \mathrm{ab}$ & $7.94 \pm 3.97 \mathrm{~b}$ & $804.30 \pm 69.10 \mathrm{a}$ & $-0.25 \pm 0.18 \mathrm{a}$ \\
\hline Gigaspora margarita & $6.38 \pm 0.15 \mathrm{a}$ & $0.07 \pm 0.04 \mathrm{a}$ & $11.92 \pm 3.97 \mathrm{~b}$ & $645.63 \pm 61.74 \mathrm{ab}$ & $-0.82 \pm 0.58 \mathrm{a}$ \\
\hline \multicolumn{6}{|c|}{ Two-way ANOVA } \\
\hline Cultivar & ** & ** & * & ns & ns \\
\hline Inoculation & * & * & ** & * & ns \\
\hline Cultivar $\times$ Inoculation & ns & ns & * & * & $\mathrm{ns}$ \\
\hline
\end{tabular}

According to these curves, $\mathrm{A}_{\max }$ and $\mathrm{A}_{\mathrm{qe}}$ of 'Baila' were significantly higher than those of 'Heiye' while LCP of 'Baila' was lower than that of 'Heiye'. AM fungal inoculation significantly affected the $\mathrm{A}_{\max }, \mathrm{A}_{\mathrm{qe}}, \mathrm{LCP}, \mathrm{LSP}$, but not the $R_{d}$ (Table 4). However, 'Baila' and 'Heiye' exhibited different response to AM fungal inoculation. The $A_{\max }, A_{\mathrm{qe}}$ and LSP of 'Baila' seedlings were not affected by AM fungal inoculation but those of 'Heiye' seedlings were significantly increased, meanwhile, LCP of 'Heiye' was significantly decreased by AM fungal inoculation (Table 4). The $R_{d}$ of both genotypes was not affected by AM fungal inoculation. These results indicate the much different response of the photosynthetic characteristics of 'Baila' and 'Heiye' seedlings to AM fungal inoculation.

\section{Relationship between plant biomass and photosynthetic} parameters

To evaluate the relative importance of photosynthetic parameters in the seedling growth, linear regression was performed between shoot biomass and $\mathrm{P}_{\mathrm{n}}, \mathrm{A}_{\max }, \mathrm{LCP}$ or LSP. It is clear that seedling growth was positively related to $P_{n}, A_{\max }$ and LSP, but negatively related to LCP (Fig. 2). However, the $R$ values of $A_{\max }, \mathrm{LCP}$ and LSP were around or above 0.5000 while that of $P_{n}$ was as low as 0.1790 . This indicates the more suitability of photosynthetic parameters derived from light response curve to predict the plant growth than the photosynthetic rate measured at a certain time point. 
470
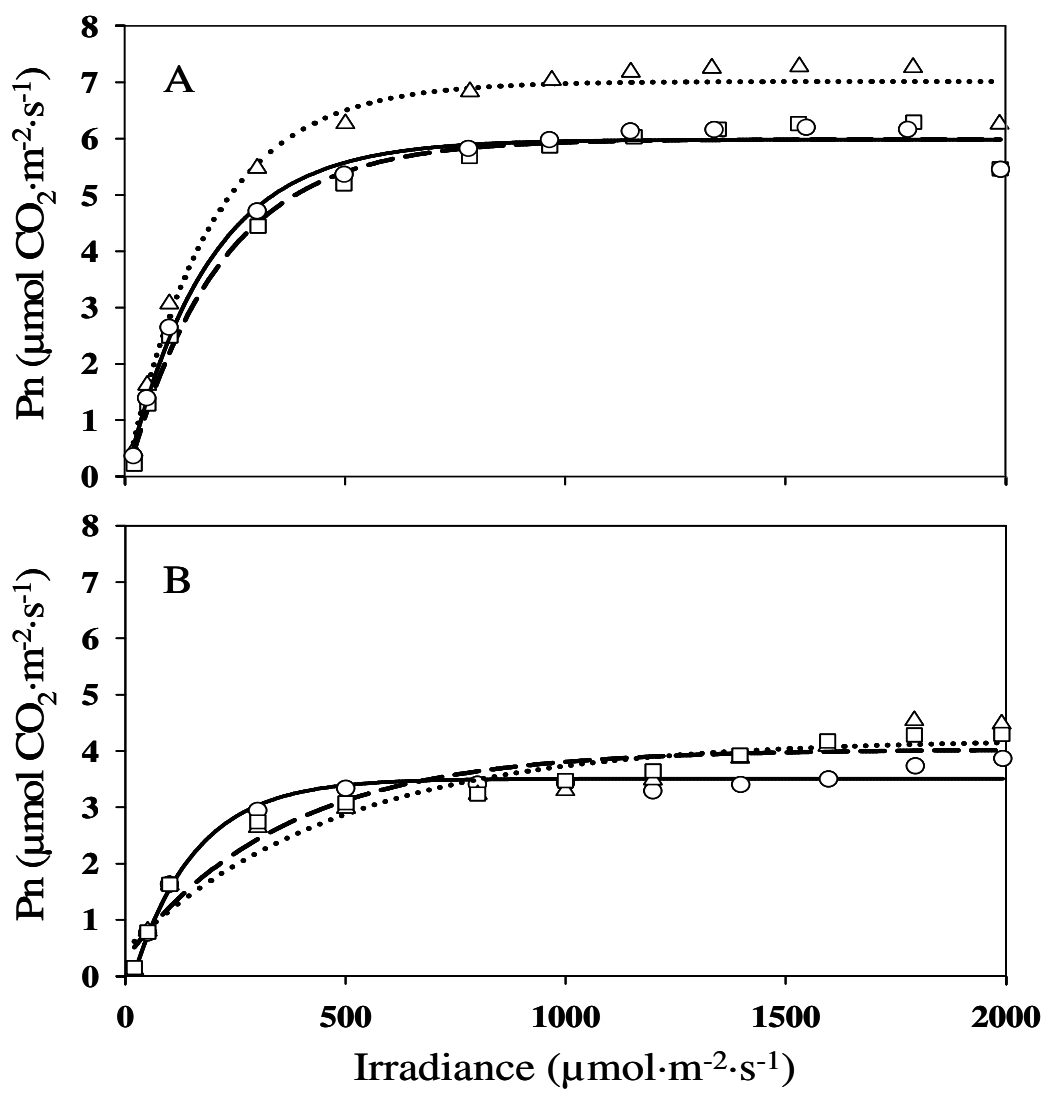

Fig. 1. Light response curves of photosynthesis as a function of irradiance for two genotypes of litchi, 'Baila' (A) and 'Heiye' (B). Plants were inoculated with Gigaspora margarita (dotted line with triangle symbols), Rhizophagus irregularis (dashed line with square symbols) or non-inoculated (solid line with circle symbols). Each data point (symbol) represents means of 10 replicates. Light curves were fitted by nonlinear regression using the Mitscherlich model equation.
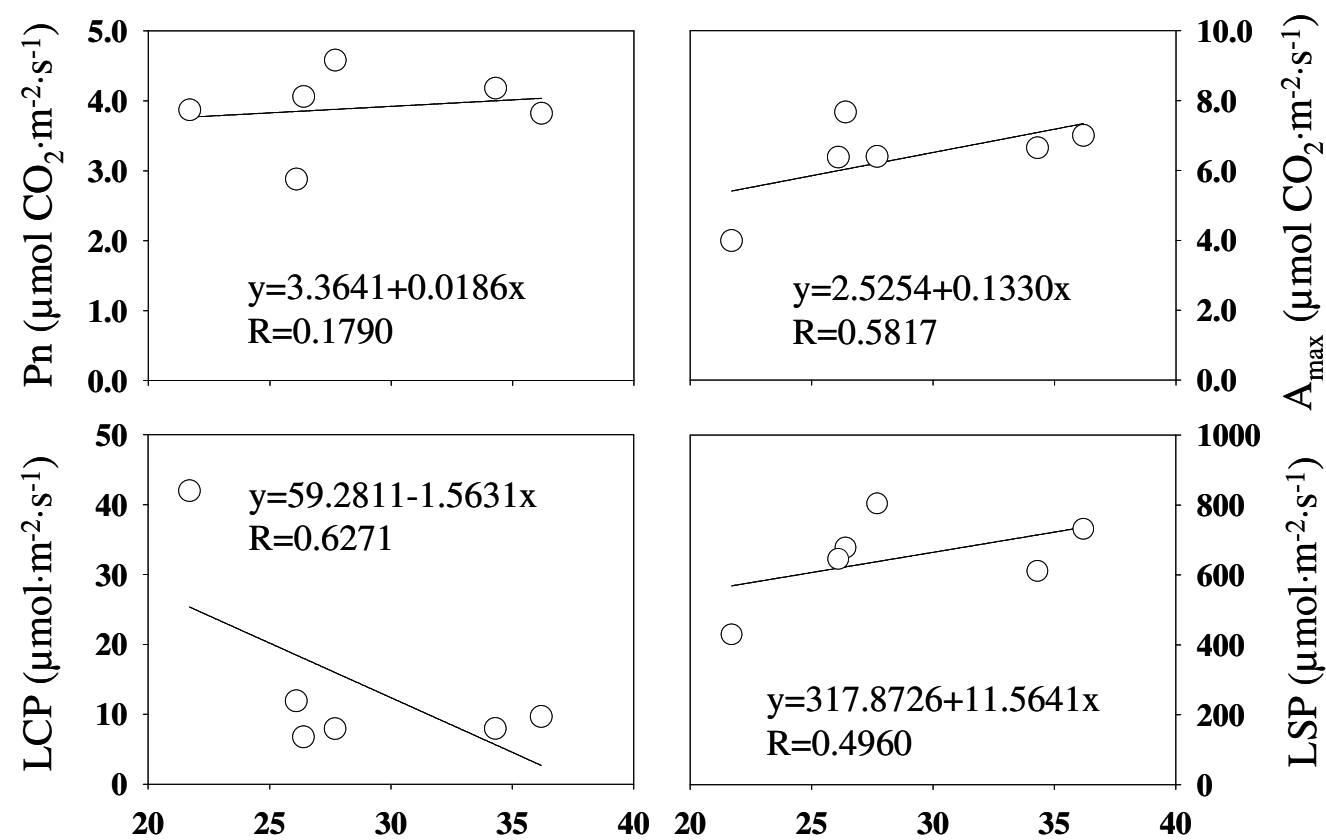

\section{Shoot FW (g)}

Fig. 2. Relationships between shoot biomass and net photosynthesis $\left(\mathrm{P}_{\mathrm{n}}\right)$, asymptote of photosynthesis $\left(\mathrm{A}_{\max }\right)$, light compensation point (LCP) or light saturation point (LSP). Each point represents the average of ten replicates. Linear regression was performed using SigmaPlot 12.5 software. 


\section{Discussion}

\section{Growth response of litchi seedlings to AM fungi}

The growth responses of plants to AM fungal colonization vary greatly. It seems that woody plants are less sensitive than non-woody plants. In a meta-analysis, Hoeksema et al. (2010) categorized plants into several functional groups and listed them in the following order in terms of growth response to AM fungi: $\mathrm{C} 4$ grasses $>$ non$\mathrm{N}$-fixing forbs $>$ non-N-fixing woody $>\mathrm{C} 3$ grasses $>\mathrm{N}$ fixing forbs $>\mathrm{N}$-fixing woody. In our study, mycorrhizal dependency of litchi rootstock seedlings is below $20 \%$. In the previous experiment, the mycorrhizal dependencies varied from $13.5 \%$ to $30.1 \%$ (Yao et al., 2005). In the airlayer system, mycorrhizal dependency was about 40\% (Janos et al., 2001). Collectively, these data suggest that litchi, as woody plant, can benefit from AM fungal inoculation to a certain extent in terms of plant growth. Habte and Manjunath (1991) have proposed five AM dependency categories, namely very highly dependent, highly dependent, moderately dependent, marginally dependent and independent. Accordingly, litchi can be classified as marginally to moderately dependent species.

\section{Photosynthetic response of litchi seedlings to AM fungi}

The promoted plant growth of litchi seedlings by AM fungi is normally attributed to enhanced nutrient uptake (Janos et al., 2001; Yao et al., 2005), however, nutrient status was not monitored in our study. Instead, the response of photosynthetic characteristics to AM fungal inoculation was investigated. Data demonstrated that AM fungal inoculation increased $A_{\max }, A_{q e}$ and LSP, and decreased LCP, but did not affected $P_{n}$. $A_{\max }, A_{q e}$, LSP and LCP are photosynthetic parameters derived from fitting curve equation (Aleric and Kirkman, 2005), while $P_{n}$ is photosynthetic parameter actually measured. Consequently, in our study, the higher photosynthesis potential as indicated by higher $\mathrm{A}_{\max }$, higher LSP and lower LCP for the inoculated rootstock seedlings can largely contribute to the increase in plant growth.

Enhanced photosynthesis by AM fungal inoculation has been extensively reported in many studies regardless of plant species (non-woody or woody plants) and growth conditions (non-stressed or stressed conditions) (Birhane et al., 2012; Zhu et al., 2012; Chen et al., 2014; Xiao et al., 2014). According to the published studies, photosynthetic rate was significantly increased by $14 \%$ due to AM fungal colonization on average (Kaschuk et al., 2009). In these reports, the parameters, $P_{n}$ and/or $A_{\max }$, were shown to increase with AM fungal inoculation. In our study, photosynthesis was promoted by AM fungi in terms of $\mathrm{A}_{\max }$, LSP and LCP, but not $P_{n}$. Meanwhile, the relationship analysis indicates that $\mathrm{A}_{\max }, \mathrm{LCP}$ and LSP seem more reliable than $P_{n}$ in our study. In fact, the AM fungal effect on $P_{n}$ was dependent on environmental factors, such as temperature and P level (Shrestha et al., 1995; Fay et al., 1996). For example, Shrestha et al. (1995) found that AM fungi enhanced $P_{n}$ only at high temperature in August but did not affect it at relatively low temperature in September. Fay et al. (1996) indicated that AM fungal effect was dependent on $\mathrm{P}$ level, increasing $\mathrm{A}_{\max }$ at low $\mathrm{P}$ level but decreasing it at high P level. In contrast, few works about AM fungal effect on $A_{\max }$, LCP or LSP was reported so far. Boldt et al. (2011) demonstrated that AM fungal inoculation significantly increased $A_{\max }$, LSP and decreased LCP, which is consistent well with the result in our study. However, Fay et al. (1996) indicated that AM fungal effect was dependent on P level, increasing $A_{\max }$ at low P level but decreasing it at high $P$ level.

Mechanisms underlying the increased photosynthesis by AM fungi include improved nutrient status (Fay et al., 1996), enhanced carbon sink (see review by Kaschuk et al., 2009 and literature therein), promoted phytohormone level (Drüge and Schonbeck, 1993). The promoted uptake of $P$, $\mathrm{K}, \mathrm{Ca}, \mathrm{Mg}, \mathrm{Mn}, \mathrm{Cu}, \mathrm{Zn}$ in litchi seedlings by AM fungi has been demonstrated (Janos et al., 2001; Yao et al., 2005) although the nutrient status was not monitored in our study. Inoculation of litchi rootstock seedlings with Glomus intraradices (namely $R$. irregularis in our study) or $G$. margarita increased IAA by 2-7 times and iPAs by 1.7-2.5 times (Yao et al., 2005). The increased phyotophormone levels by AM fungi may be fungal origin or plant origin induced by colonization (Ludwig-Müller, 2010). It can be speculated that the changes in phytohormones induced by AM fungal inoculation are probably responsible for the increased photosynthesis of litchi rootstock seedlings in our study.

\section{Difference in the responses of two cultivars to AM fungi}

It has been revealed that AM fungal inoculation effect depends on the rootstock genotypes of citrus (Graham $e t$ al., 1997). They found that the mycorrhizal dependencies of five genotypes were much different, with volkamer lemon (Citrus volkameriana Tan. and Pasq.) ranking the highest and trifoliate orange [Poncirus trifoliate (L.) Raf.] the lowest. In our study, only two litchi rootstock genotypes were estimated, however, they responded much differently to AM fungal inoculation. 'Heiye' showed positive response while 'Baila' negative. On one hand, this result indicates the necessity to screen appropriate rootstock (e.g. 'Heiye' in our study) in the grafting system of litchi if AM technology is considered. On the other hand, the difference in two fungal species should also be taken into consideration.

Our study was conducted in the nursery condition, and thus the obtained results can apply to the litchi propagation system. The positive response of 'Heiye' rootstock seedlings to AM fungi suggests the potential application in of AM fungi in litchi nursery. It is well recognized that AM fungal inoculation promoted the seedling growth in both grafting system (our study) and air-layer system (Janos et al., 2001; Sagar and Roy, 2013) due to improved photosynthesis (our study) or nutrient status (Janos et al., 2001). The successful application of AM fungi in propagation system of citrus has been well established for decades (Menge et al., 1982). For litchi, in the grafting propagation system using AM technology, 'Heiye' genotype should be the first choice as rootstock, however, evaluation with more genotypes is also recommended. 
472

\section{Conclusions}

In conclusion, the inoculation of litchi rootstock seedlings with AM fungi affected the plant growth with differences between two genotypes in nursery condition. 'Heiye' responded positively while 'Baila' responded negatively to $A M$ fungi. AM fungi increased the $A_{\text {max }}, A_{q e}$ and LSP and decreased the LCP of 'Heiye', but did not affect those of 'Baila'. These differences could be responsible for the different growth responses of two genotypes to AM fungi. Due the prevalence of propagation with grafting in litchi nursery in China, our study highlights the potential application of AM technology in this system. However, precautions should be taken to select appropriate genotypes, and we recommend 'Heiye' according to the results in our study.

\section{Acknowledgements}

The authors are thankful to professor Zixing Ye in College of Horticulture, South China Agricultural University for his kind provision with substrate and technical assistance in nursery management. This work was financially supported by the Natural Science Foundation of China (31570395, 31270448), Guangdong Science and Technology Projects (2016A020210071, 2016B090918090, 2015TX01N036), and The Innovationdriven Development Capability Construction Program of GDAS (2017GDASCX-0402).

\section{References}

Aleric KM, Kirkman LK (2005). Growth and photosynthetic responses of the federally endangered shrub, Lindera melissifolia (Lauraceae), to varied light environments. American Journal of Botany 92:682-689.

Asmar SA, Castro EM, Pasqual M, Pereira FJ, Soares JDR (2013). Changes in leaf anatomy and photosynthesis of micropropagated banana under different silicon sources. Scientia Horticulturae 161:328-332.

Azcón-Aguilar C, Barea JM (1997). Applying mycorrhizal biotechnology to horticulture: significance and potentials. Scientia Horticulturae 68:1-24.

Birhane E, Sterck FJ, Fetene M, Bongers F, Kuyper TW (2012). Arbuscular mycorrhizal fungi enhance photosynthesis, water use efficiency, and growth of frankincense seedlings under pulsed water availability conditions. Oecologia 169:895-904.

Boldt K, Pörs Y, Haupt B, Bitterlich M, Kühn C, Grimm B, Franken P (2011). Photochemical processes, carbon assimilation and RNA accumulation of sucrose transporter genes in tomato arbuscular mycorrhizal.Journal of Plant Physiology 168:1256-1263.

Chen YY, Hu CY, Xiao JX (2014). Effects of arbuscular mycorrhizal inoculation on the growth, zinc distribution and photosynthesis of two citrus cultivars grown in low-zinc soil. Trees 28:1427-1436.

Drüge U, Schonbeck F (1993). Effect of vesicular-mycorrhizal infection on transpiration, photosynthesis and growth of flax (Linum usitatismum L.) in relation to cytokinin levels. Journal of Plant Physiology 141:40-48.

Graham JH, Duncan LW, Eissenstat DM (1997). Carbohydrate allocation patterns in citrus genotypes as affected by phosphorus nutrition, mycorrhizal colonization and mycorrhizal dependency. New Phytologist 135:335-343.
Fay P, Mitchell DT, Osborne BA (1996). Photosynthesis and nutrient-use efficiency of barley in response to low arbuscular mycorrhizal colonization and addition of phosphorus. New Phytologist 132:425433.

Habte M, Manjunath A (1991). Categories of vesicular-arbuscular mycorrhizal dependency of host species. Mycorrhiza 1:3-12.

Hoeksema JD, Chaudhary B, Gehring CA, Johnson N, Karst J, Koide RT, Pringle A, Zabinski C, Bever JD, Moore JC, Wilson GWT, Klironomos JN, Umbanhowar J (2010). A meta-analysis of contextdependency in plant response to inoculation with mycorrhizal fungi. Ecology Letter 13:394407.

Janos DP, Schroeder MS, Schaffer B, Crane JH (2001). Inoculation with arbuscular mycorrhizal fungi enhances growth of Litchi chinensis Sonn. trees after propagation by air-layering. Plant and Soil 233:85-94.

Jiang Y, Gao H, Zhang M (2012). Lychee (Litchi). In: Siddiq M (Ed). Tropical and Subtropical Fruit: Postharvest Physiology, Processing and Packaging, 1st edn. John Wiley \& Sons, Inc, New Delhi, India, pp 241258.

Kaschuk G, Kuyper TW, Leffelaar PA, Hungria M, Giller KE (2009). Are the rates of photosynthesis stimulated by the carbon sink strength of rhizobial and arbuscular mycorrhizal symbioses? Soil Biology and Biochemistry 41:1233-1244.

Koske RE, Gemma JN (1989). A modified procedure for staining roots to detect VA mycorrhizas. Mycological Research 92:486-488.

Ludwig-Müller J (2010). Hormonal responses in host plants triggered by arbuscular mycorrhizal fungi. In: Koltai H, Kapulnik Y (Eds). Arbuscular Mycorrhizas: Physiology and Function, 2nd edn. Springer, New York pp 169-190.

McGonigle TP, Miller MH, Evans DG, Fairchild GL, Swan JA (1990). A new method which gives an objective measure of colonization of roots by vesicular-arbuscular mycorrhizal fungi. New Phytologist 115:495501.

Menge JA, Jarrell WM, Labanauskas CK, Ojala JC, Huszar C, Johnson ELV, Sibert D (1982). Predicting mycorrhizal dependency of Troyer citrange on Glomus fasciculatus in California citrus soils and nursery mixes. Soil ScienceSociety of America Journal 46:762-768.

Menzel C (2002). The lychee crop in Asia and the pacific. Bangkok, Thailand.FAO/RAPPublication.

Mridha MAU, Dhar PP (2007). Biodiversity of arbuscular mycorrhizal colonization and spore population in different agroforestry trees and crop species growing in Dinajpur, Bangladesh. Journal of Forest Research 18:91-96.

Rillig MC (2004). Arbuscular mycorrhizae and terrestrial ecosystem processes. Ecology Letter 7:740-754.

Sagar P, Roy AK (2013). Efficacy of arbuscular mycorrhizal fungi for litchi [Litchi chinensis (Gaertn.) Sonn] marcots inoculation in nursery.Journal of Mycopathology Research 51:141-144.

Sensoy S, Ocak E, Demir S, Tufenkci S (2013). Effects of humic acid, whey and arbuscular mycorrhizal fungi (AMF) applications on seedling growth and Fusarium wilt in zucchini (Cucurbita pepo L.). Journal of Animal and Plant Sciences 23:507-513.

Sharma SD, Kumar P, Raj H (2009). Isolation of arbuscular mycorrhizal fungi and Azotobacter chroococcum from local litchi orchards and evaluation of their activity in the air-layers system. Scientia Horticulturae 
123:117-123.

Shrestha YH, Ishii T, Kadoya K (1995). Effect of vesicular-arbuscular mycorrhizal fungi on the growth, photosynthesis, transpiration and the distribution of photosynthates of bearing Satsuma mandarin trees. Journal of JapaneseSociety of Horticultural Science 64:517-525.

Singh PR, Prasad V (2006). Occurrence and population dynamics of vesicular arbuscular mycorrhizae in the Indian orchards of litchi (Litchi chinensis Sonn), aonla (Phyllanthus emblica L.) and banana (Musa paradisiaca L.). Asian Journal of Biological Science 1:154-156.

Wang G, Innes J, Yang Y, Chen S, Kizyzanowski J, Xie J, Lin W (2012). Extent of soil erosion and surface runoff associated with large-scale infrastructure development in Fujian Province, China. Catena 89:2230.

Xiao JX, Hu CY, Chen YY, Yang B, Hua J (2014). Effects of low magnesium and an arbuscular mycorrhzial fungus on the growth, magnesium distribution and photosynthesis of two citrus cultivars. Scientia Horticulturae 177:1420.

Yao Q,Zhu HH, Chen JZ (2005). Growth responses and endogenous IAA and iPAs changes of litchi (Litchi chinensis Sonn.) seedlings induced by arbuscular mycorrhizal fungal inoculation. Scientia Horticulturae 105:145-151.
Yao Q, Wang LR, Zhu HH (2009). Effect of arbuscular mycorrhizal fungal inoculation on root system architecture of trifoliate orange (Poncirus trifoliata L. Raf.) seedlings. Scientia Horticulturae 121:458-461.

Yao Q, Yang R, Long L, Zhu HH (2014). Phosphate application enhances the resistance of arbuscular mycorrhizae in clover plants to cadmium via polyphosphate accumulation in fungal hyphae. Environmental and Experimental Botany 108:63-70.

Zhu HH, Yao Q (2004). Localized and systemic increase of phenols in tomato roots induced by Glomus versiforme inhibits Ralstonia solanacearum. Journal of Phytopathology 152:537-542.

Zhu HH, Yao Q, Sun XT, Hu YL (2007). Colonization, ALP activity and plant growth promotion of native and exogenous AM fungi in an acid soil. Soil Biology and Biochemistry 39:942-950.

Zhu XC, Song FB, Liu SQ, Liu TD, Zhou X (2012). Arbuscular mycorrhizae improves photosynthesis and water status of Zea mays $\mathrm{L}$. under drought stress. Plant, Soil and Environment 58:186-191.

Zou YN, Srivastava AK, Wu QS, Huang YM (2014). Increased tolerance of trifoliate orange (Poncirus trifoliata) seedlings to waterlogging after inoculation with arbuscular mycorrhizal fungi. Journal of Animal and PlantSciences 24:1415-1420. 